Estudios Constitucionales, Año 16, No 2, 2018, pp. 369-402

ISSN 07180195

Centro de Estudios Constitucionales de Chile Universidad de Talca

"Diagnóstico sobre las relaciones entre el derecho internacional y el derecho interno. El caso colombiano"

Paola Andrea Acosta Alvarado - Juana Acosta-López -

Julián Huertas Cárdenas - Daniel Rivas-Ramírez

\title{
DIAGNÓSTICO SOBRE LAS RELACIONES ENTRE EL DERECHO INTERNACIONAL Y EL DERECHO INTERNO. EL CASO COLOMBIANO*
}

\author{
DIAGNOSIS ABOUT THE RELATIONS BETWEEN INTERNATIONAL \\ LAW AND DOMESTIC LAW: THE COLOMBIAN CASE
}

\author{
Paola Andrea Acosta Alvarado* \\ Universidad Externado de Colombia \\ paola.acosta@uexternado.edu.co \\ JuANa ACOSTA-LóPez ${ }^{* * *}$ \\ Universidad de La Sabana \\ juanacl@unisabana.edu.co \\ JULIÁN HuerTAS CÁRDENAS * $^{* * *}$ \\ Universidad de La Sabana \\ julian.huertas1@unisabana.edu.co \\ DANIEL Rivas-RAmíReZ $Z^{* * * *}$ \\ Universidad Externado de Colombia \\ daniel.rivas@uexternado.edu.co
}

RESUMEN: Cada día se hacen más evidentes las constantes relaciones e interacciones entre el derecho internacional y el derecho nacional, hasta el punto de replantearse las antiguas nociones del monismo

\footnotetext{
* Trabajo recibido el 15 de febrero de 2018 y aprobado el 9 de septiembre de 2018.

Las ideas que se exponen en este documento fueron desarrolladas a profundidad por los autores en el libro editado por Acosta, Acosta y Rivas (2017).

** Doctora en Derecho Internacional y Relaciones Internacionales del Instituto Ortega y Gasset de la Universidad Complutense de Madrid. Editora de la Revista Derecho del Estado y profesora de Derecho Internacional de la Universidad Externado de Colombia (Bogotá, Colombia).

${ }^{* * *}$ LLM en International Legal Studies de la New York University. Magíster en Derechos Humanos y Democratización de la Universidad Externado de Colombia. Directora de profesores e investigación de la Facultad de Derecho y Ciencias Políticas de la Universidad de La Sabana (Bogotá, Colombia).

**** Magíster en Derecho Internacional de la Universidad de La Sabana. Profesor del Departamento de Derecho Internacional de la Universidad de La Sabana (Bogotá, Colombia).

***** Egresado de la Facultad de Derecho de la Universidad Externado de Colombia. Joven investigador del Departamento de Derecho Constitucional y Coordinador editorial de la Revista Derecho del Estado de la Universidad Externado de Colombia (Bogotá, Colombia).
} 
y el dualismo. Este artículo presenta los resultados del proyecto de investigación conjunto de las universidades de La Sabana y Externado de Colombia en el que se pretendia realizar un estudio exhaustivo de la forma en la que la Corte Constitucional de Colombia ha tratado las relaciones entre ambos ordenamientos en su jurisprudencia. En tal sentido, las páginas que siguen explican la metodología de este proyecto, los principales hallazgos transversales a la jurisprudencia constitucional de nuestro pais y, finalmente, presenta algunas conclusiones relacionadas con el papel que el juez constitucional ha ocupado, y el que debería ocupar en la articulación de ambos ordenamientos.

ABSTRACT: Day by day the interactions between international and domestic law prove that it's necessary to rethink these relations disregardig monism and dualism. This article presents the results of a research project developed between the Universities La Sabana and Externado de Colombia, in which the main objective was to make an exhaustive study of how the Colombian Constitutional Court has treated in its jurisprudence the relations between both legal systems. In that order of ideas, the following pages explain the methodology used during the project, the main findings across the constitutional national jurisprudence, and at the end, some considerations regarding the role that the constitutional judge has occupied and the one that should fulfill in the articulation between both, international and domestic law.

Palabras CLAVE: Derecho internacional, derecho nacional, Colombia, relaciones interodinamentales, monismo, dualismo, pluralismo jurídico.

KEY WORDS: International Law, Domestic Law, Colombia, relations between legal orders, monism, dualism, legal pluralism.

Hace varios números publicábamos en esta misma Revista algunas reflexiones sobre las nuevas relaciones entre el derecho internacional y el derecho interno en Latinoamérica ${ }^{1}$. En aquel entonces nos referíamos al monismo y al dualismo como zombis, muertos vivientes que debían, de una buena vez, pasar a mejor vida. Como relevo de dichas teorías vaticinábamos la creación de un Frankenstein, una mezcla entre lo bueno del monismo y el dualismo, cuya puesta en marcha dependía de un nuevo corazón: la heterarquía y las herramientas para la solución de conflictos normativos caso a caso.

Estas ideas se basaban, sobre todo, en instintos, en análisis dispersos de algunos casos particulares, pero no se respaldaban en un diagnóstico integral de las normas constitucionales y legales sobre la materia, ni de la práctica judicial. Sin embargo, los últimos años hemos dedicado nuestro trabajo a la construcción de un análisis sistemático, especialmente de la práctica judicial nacional, en torno al discurso y al uso del derecho internacional. Tal investigación comprobó nuestra intuición: no existe claridad alguna sobre el qué y el cómo de la relación entre el derecho internacional y el derecho interno; gran parte del discurso judicial sobre

1 Acosta (2016), pp. 15-60. 
este asunto gira en torno a la confusión conceptual y a la manipulación teórica de viejos modelos inútiles ante la actual dinámica de dicha relación.

A renglón seguido, queremos compartir los resultados de nuestra investigación, centrados en un caso particular: el colombiano. Para ello, explicaremos la metodología que usamos para la búsqueda y sistematización de la información, expondremos los resultados más relevantes de ese esfuerzo y daremos cuenta de algunas reflexiones construidas con base en dichos resultados.

\section{El GIReDIN COlOMbia y SU PROCESO DE INVESTIGACión}

El proceso de sistematización que presentamos a renglón seguido tuvo lugar en el marco del trabajo del Grupo de Interés sobre las nuevas Relaciones entre el Derecho Internacional y el derecho Nacional de la Sociedad Latinoamericana de Derecho Internacional (SLADI-GIReDIN). Este grupo, creado hace cuatro años, se propuso hacer un diagnóstico sobre cómo han entendido los jueces constitucionales de la región la articulación entre ambos ordenamientos para, desde allí, develar su creciente complejidad, la insuficiencia de los modelos teóricos tradicionales y los retos que esto implica para los funcionarios estatales. Tal esfuerzo contó con participantes de diversos países: Argentina, Bolivia, Brasil, Guatemala, Perú y, por supuesto, Colombia.

El equipo colombiano estuvo articulado por dos universidades, La Sabana y el Externado, liderado por cuatro investigadores (quienes suscribimos este texto) y apoyado por más de una decena de estudiantes de pregrado ${ }^{2}$. En este sentido, la información que se presenta a continuación es el producto de un esfuerzo colectivo cuyo trabajo cimienta las reflexiones que se presentan en la tercera parte de este texto.

Lo primero que debemos aclarar son los contornos de la investigación y su metodología. En el caso colombiano, originalmente se pretendía hacer un estudio de toda la jurisprudencia constitucional que hubiera tenido en cuenta normas

2 Queremos hacer un reconocimiento especial y extenderles nuestro agradecimiento a aquellos estudiantes de ambas universidades que participaron en el desarrollo del proyecto. En concreto, un reconocimiento a Ana María Idárraga, Andrea Jiménez, Andrea Pertuz, Angelita Losada, Camilo Peinado, Cindy Vanessa Espitia, Daniela Medina, Jeffrey León, Juan Camilo Hernández, Juan Diego Ramírez, Juan Pablo Acosta, Juanita Chavarría, Laura Cristina Camacho Lina Morales, Mery Helen Ocampo, Natalia Isabel Castellanos, Paula García, Sergio Severiche, Wilmar Peña y al antiguo equipo de monitores del Departamento de Derecho Constitucional de la Universidad Externado de Colombia: Alejandra Muñoz, Alejandra Osorio, Camila Vega, Camila Medina, Juan Camilo Caicedo y Marcelo Lozada. 
internacionales, desde 1992 hasta 2014 (año en el que se comenzó el proyecto de pesquisa). Lo que se tenía en mente era determinar cómo se había construido la relación entre derecho internacional y derecho interno, especialmente en lo que tiene que ver con las preguntas en torno al lugar que las normas de origen internacional ocupan en el sistema normativo colombiano, a los modelos teóricos que al respecto sigue el juez constitucional, las reglas de solución de conflictos normativos, entre otros importantes asuntos.

Para tal efecto, los estudiantes adscritos al proyecto comenzaron un barrido de jurisprudencia en la relatoría de la Corte Constitucional, con base en un listado de palabras claves. Conceptos tales como, tratado, convención, convenio, acuerdo, derecho internacional, derechos humanos, interamericana, conferencia, comercio internacional e inversión extranjera, entre otros, sirvieron como derrotero para la construcción de las primeras listas de jurisprudencia en torno al asunto central del proyecto.

El resultado de este primer paso fue tan abrumador que se tomó la decisión de reducir la muestra respecto de la cual los estudiantes deberían hacer la lectura detallada de la jurisprudencia. Para tal efecto, tuvimos en cuenta un factor meramente temporal gracias al cual se redujo la muestra a las providencias que habían sido proferidas en el período comprendido entre el año dos mil nueve (2009) y dos mil dieciséis (2016 -año de cierre de la fase de investigación-). Es así como la base jurisprudencial sobre la que trabajamos quedó conformada por un total de 461 providencias. Una vez conformada la muestra, los investigadores se dedicaron a la lectura detallada de las sentencias y a diligenciar una ficha de análisis diseñada por las directoras del proyecto en la que se especificaban los datos relevantes para las preguntas centrales de la investigación (ver anexo).

Terminada esta primera fase, el equipo de investigación se organizó en subgrupos y se asignó el trabajo para la segunda fase atendiendo a un criterio temático. Así, se identificaron al menos nueve grandes temas que eran reiterativos en la jurisprudencia de la Corte Constitucional. Estos son: el derecho internacional de los derechos humanos, el derecho internacional humanitario, el derecho penal internacional, la justicia transicional, el derecho internacional del medio ambiente, el derecho del comercio internacional, el derecho internacional de las inversiones y el derecho internacional relacionado con asuntos territoriales.

Atendiendo a estas áreas temáticas, cada equipo de trabajo se dedicó al análisis detallado de las sentencias que se habían pronunciado sobre la cuestión asignada y que habían sido sistematizadas en la primera fase. Además, de esto, se sugirió 
servirse de la metodología bola de nieve 3 para poder abarcar la jurisprudencia expedida en el período de tiempo cubierto por el proyecto, pero, también, aquella relevante de períodos anteriores si es que ello resultaba necesario o relevante para responder a los interrogantes planteados.

Dichas preguntas respondían a las inquietudes centrales de la investigación y gracias a ellas se pudo construir el análisis transversal que se presentará en la tercera parte de este texto. Por el momento basta enlistarlas: ¿Cuál es la rama del derecho internacional público sobre la que se pronuncia o invoca la providencia? ¿Cuál es la naturaleza de la norma internacional a la que se acude? ¿Cuál es la razón por la cual se utilizan las normas internacionales en esa providencia? ¿Cuál es la jerarquía que se le atribuye a cada una de las fuentes del derecho internacional en la providencia? ¿En caso tal que exista un conflicto normativo entre los dos ordenamientos, el juez constitucional se encarga de resolverlo? ¿El juez constitucional se pronuncia sobre la figura del bloque de constitucionalidad? ¿El juez constitucional desarrolla implícita o explícitamente el concepto de control de convencionalidad? ¿El juez constitucional se pronuncia de manera explícita sobre el modelo teórico que acoge sobre las relaciones entre el derecho internacional y el derecho interno? ¿En la providencia se utilizan los principios del pluralismo constitucional? ¿Qué tipo de cláusula de articulación se invoca?

A continuación, ofrecemos algunos de los datos relevantes de la primera fase del trabajo, esto es, los aspectos meramente cuantitativos del proceso. En el tercer acápite se presentará las conclusiones del análisis transversal de los diversos ejes temáticos.

\section{LOS DATOS RELEVANTES QUE ARROJA LA PRIMERA LECTURA DE LA JURISPRUDENCIA CONSTITUCIONAL SOBRE EL DERECHO INTERNACIONAL}

En este apartado nos limitaremos a exponer algunos datos relevantes producto de la primera etapa de análisis, agrupados en seis categorías: las ramas del derecho internacional que se reflejan en la jurisprudencia constitucional; la naturaleza de la norma internacional que utiliza -o nombra- la Corte; jerarquía normativa y resolución de conflictos; el bloque de constitucionalidad y el control de convencionalidad; los modelos teóricos de las relaciones entre el derecho internacional y el derecho interno y las cláusulas de articulación.

\footnotetext{
3 Entendemos por efecto bola de nieve la remisión a las sentencias que se encontraban referenciadas en las sentencias objeto de análisis. De esta manera, se pudo abarcar no solo las sentencias que se habrían identificado y analizado en la ficha metodológica, sino también aquellas que eran anteriores al año 2009.
} 
$\checkmark$ Las ramas del derecho internacional que se reflejan en la jurisprudencia constitucional

Para empezar, la primera pregunta que se formuló -y que a su vez sirvió como base para la segunda fase del proyecto- fue aquella que se preguntaba por cuáles eran los temas del derecho internacional que le preocupaban e interesaban al juez constitucional. Al respecto encontramos que la gran mayoría de las sentencias y autos, invocaban de una u otra manera el derecho internacional de los derechos humanos. Lo que inició como una respuesta intuitiva, después se vio reflejado en los números, pero también en los hallazgos sustanciales de la investigación. La razón de este uso predominante de los derechos humanos es evidente: todos los instrumentos internacionales sobre este asunto hacen parte del bloque de constitucionalidad.

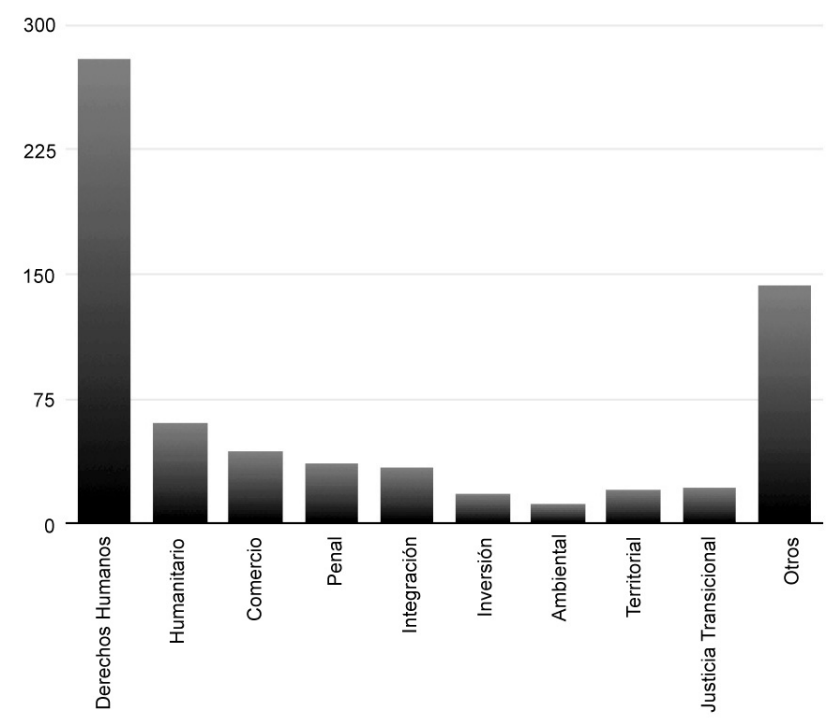

Ahora bien, si revisamos el otro extremo, los temas sobre los cuales menos se pronuncia son los relacionados con el derecho internacional del medio ambiente y el derecho internacional de las inversiones. Siguiendo con el razonamiento anterior, parecería lógico por cuanto se trata de normas que no hacen parte del bloque de constitucionalidad y por tanto no sirven como un parámetro de control constitucional. Sin embargo, cabría preguntarse si aún al no ser un criterio que en principio debería usar el juez constitucional e incluso al no estar acostumbrados a echar mano de estas, deberíamos olvidar que tienen alta relevancia por cuanto se trata de obligaciones internacionales cuyo incumplimiento podría llevar a una gravísima responsabilidad internacional. 


\section{$\checkmark$ La naturaleza de la norma internacional que utiliza -o nombra-la Corte}

Un segundo tema por el que se preguntó fue el tipo de norma que se invoca en la jurisprudencia constitucional. Las estadísticas son bastante reveladoras por cuanto demuestran que, para el juez constitucional, parecería que la única forma de creación de obligaciones internacionales que importara y que generase efectos jurídicos en el ordenamiento nacional serían los tratados internacionales. Casi el ochenta por ciento de las veces en las que se habló del derecho internacional público en las providencias fue sobre tratados.

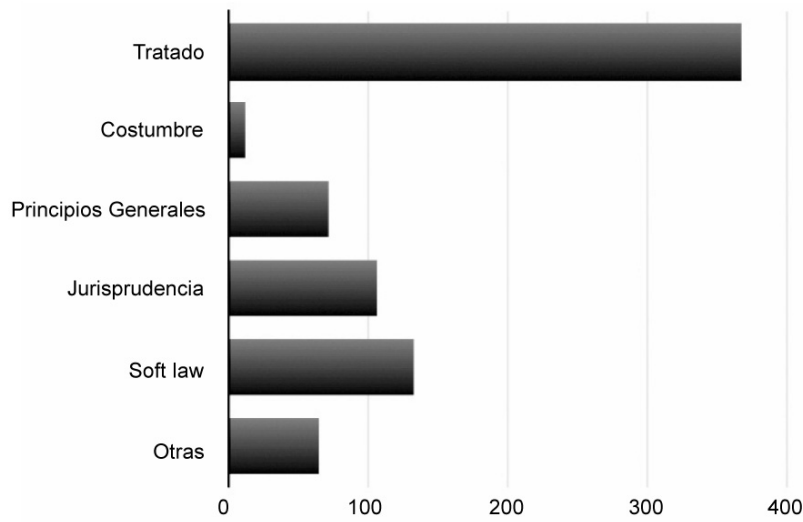

Por el contrario, el intérprete constitucional a duras penas menciona en sus sentencias fuentes igual o incluso más importantes -en algunos casos- que los tratados, como es el caso del derecho consuetudinario.

Adicionalmente, vale la pena destacar que el juez constitucional hace un esfuerzo por tener en cuenta el Derecho internacional en sus providencias. Tanto así que en la mayoría de las ocasiones - casi el ochenta por ciento- es él quien trae a colación las normas internacionales motu proprio. No podemos decir lo mismo por parte de la labor adelantada por demandantes e intervinientes por cuanto conocemos su opinión de manera indirecta a través de los resúmenes elaborados por la Corte y, por tanto, no tenemos certeza de lo que dicen o hacen.

\section{$\checkmark$ Jerarquía normativa y resolución de conflictos}

Tras la identificación de las normas internacionales utilizadas por la Corte, convenía preguntarse si en algún caso el Tribunal les asignaba algún estatus o rango dentro de nuestro sistema normativo. A la hora de responder la ficha metodológica se daba la posibilidad de señalar cada rango que se le daba a cada una de las normas; sin embargo, debido a los escasos resultados, solo amerita ilustrar 
el caso de los tratados internacionales. En el resto de normas, más del noventa y cinco por ciento de las veces el juez no se pronunció al respecto.

Ahora bien, pese a que el juez se pronunció sobre el estatus de los tratados, también es verdad, por una parte, que la gran mayoría de las veces omitió aclarar este asunto y, por la otra, que las veces en las que se pronunció dio respuestas contradictorias asignando a los tratados diferentes rangos, dependiendo de la materia de la que se trate.

Partiendo del hecho de que en la mayoría de los casos no hay un reconocimiento de ninguna jerarquía para la norma internacional y sumándole a ello que en los más de los casos en los se habla de derecho internacional en las providencias es porque se trata del control automático de constitucionalidad, en casi ninguna providencia se evidencia de manera flagrante un conflicto normativo interodinamental más allá que el propio de un juicio de constitucionalidad. Sin embargo, en la generalidad de los casos en los que había conflicto, se trataba de uno entre normas internacionales y normas de rango legal.

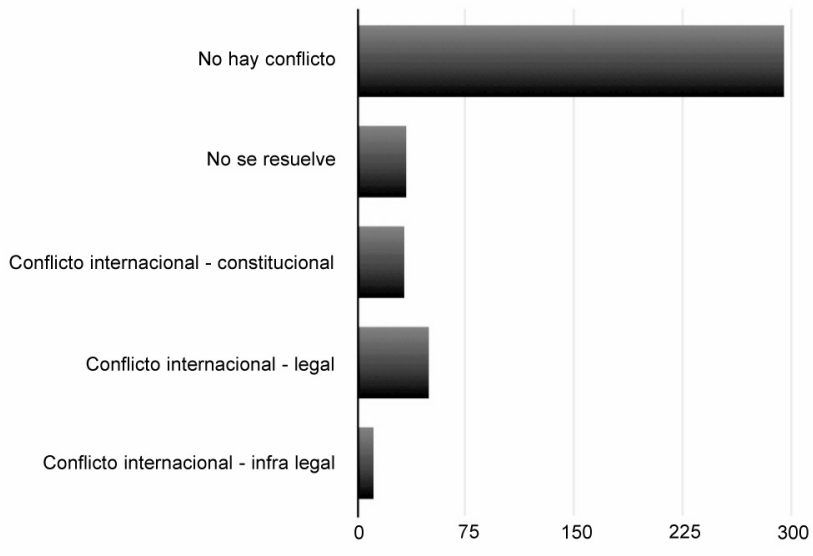

\section{$\checkmark$ Bloque de constitucionalidad y control de convencionalidad}

La figura del bloque de constitucionalidad resulta ser una de las más utilizadas dentro de la jurisprudencia de la Corte Constitucional. Esto en parte se debe a dos razones. En primer lugar, a que el bloque se usa como parámetro de constitucionalidad ya sea cuando se trata del bloque en stricto sensu ${ }^{4}$ o lato sensu (así,

\footnotetext{
4 Vale la pena recordar que el bloque de constitucionalidad stricto sensu se integra por todas aquellas normas y principios que aun cuando no están contempladas expresamente en el texto constitucional,
} 
en el 38\% de los casos). Por otra parte -en la mayoría de los casos restantes-, a que la figura se usa para excluir otras normas del derecho internacional como parámetros de constitucionalidad.

Adicionalmente, debemos destacar que el bloque de constitucionalidad obra no solo como un parámetro de constitucionalidad, sino también como una amalgama o un catalizador de las normas internacionales dentro del ordenamiento jurídico colombiano. En particular vemos que se vuelve una herramienta ideal para la ampliación del catálogo de bienes jurídicos protegidos constitucionalmente y permite una protección de los derechos humanos en una mayor dimensión. Lo anterior se ve reflejado en que la mayoría de las ocasiones en las que la Corte Constitucional hace una mención explícita a la figura, es cuando estamos ante el dispositivo amplificador del artículo 93 de la Carta.

Aunado a lo anterior, encontramos que hay otra institución -que también se traduce en una herramienta de armonización entre los dos ordenamientos y termina protegiendo principalmente los derechos humanos- que ha sido utilizada por la Corte Constitucional. Nos referimos al control de convencionalidad, el cual se encuentra presente en la mayoría de los casos en los que se desarrolla la idea del bloque de constitucionalidad.

En concreto, encontramos de nuestro primer acercamiento a la jurisprudencia constitucional que se trata de una figura que el juez constitucional aplica de manera automática a la hora de dirimir la situación que se le presenta, mas no lo señala ni desarrolla explícitamente. Es decir, aun cuando la Corte ha sido responsable y juiciosa en la utilización de normas interamericanas como parámetro de constitucionalidad o, en su defecto, como herramienta de armonización para resolver un conflicto, las más de las veces, el esfuerzo por definir, explicar y dimensionar la figura la han hecho unos pocos magistrados a través de salvamentos y aclaraciones de votos -el 3\% de las providencias-, en el resto de los casos el control se hace, pero no se "bautiza", es decir, no se le denomina propiamente control de convencionalidad.

al integrarse por mandato constitucional, cobran un rango constitucional, e. g., Normas de Derechos Humanos en virtud del artículo 93 de la Constitución. Por otro lado, el bloque de constitucionalidad lato sensu se integra de normas que no tienen tal rango, pero que en todo caso, al tener una jerarquía mayor que la de las leyes ordinarias, pueden ser utilizadas como un parámetro de legalidad y constitucionalidad, e. g., las leyes estatutarias. Al respecto se pueden ver Corte Constitucional de Colombia, Sentencia C-191, del 6 de mayo de 1998 y Corte Constitucional de Colombia, Sentencia C-582 del 11 de agosto de 1999. 


\section{$\checkmark$ Modelos teóricos de las relaciones entre el derecho internacional y el derecho interno}

Una pregunta esencial para los efectos de la investigación es la que trata sobre los modelos teóricos que acoge la Corte Constitucional en sus providencias. Si bien la regla general es la de no pronunciarse en absoluto sobre este tema, lo normal, cuando lo hace, es que se catalogue o defina nuestro modelo como monista o monista moderado. Tanto es así que tan solo en el $1 \%$ de los casos mencionó al dualismo dentro de sus sentencias y solamente en una ocasión se atrevió a nombrar otras teorías como el pluralismo constitucional.

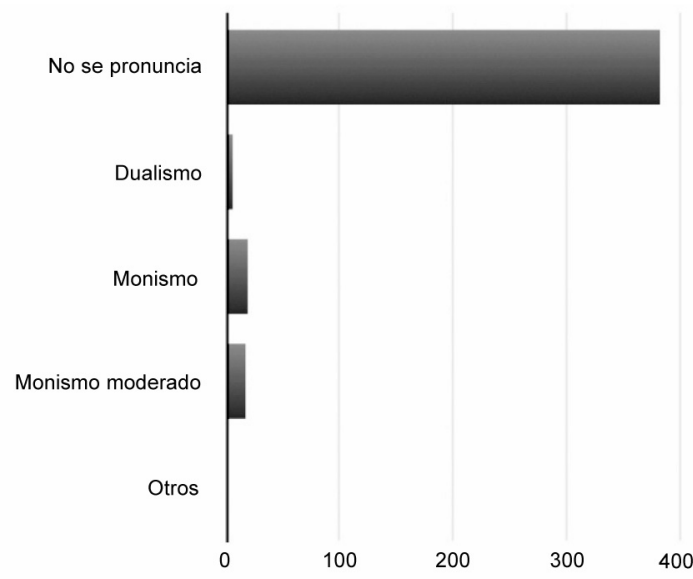

Al ver que la Corte no fue ni es consciente de la opción del pluralismo constitucional, a la hora de llenar la ficha metodológica se permitió la opción de señalar si se identificaba el uso de alguno de los principios de este modelo teórico. Resultó sorprenderte descubrir que en el 10\% de los casos se hizo referencia a alguno de los mecanismos del pluralismo: el efecto útil, la interpretación conforme, la subsidiariedad, el debido proceso o los derechos humanos para efectos de la resolución de un conflicto normativo.

\section{$\checkmark$ Cláusulas de articulación}

Finalmente, con relación al tema del pluralismo constitucional, a la hora de realizar el análisis de las providencias, se procuró identificar, dentro de las normas jurídicas que utilizaba la Corte para tomar su decisión, a qué cláusulas de articulación podrían corresponder. Para este propósito, se sugirieron e identificaron cinco tipos de cláusulas diferentes y se cruzaron con tres rangos normativos. Las cláusulas correspondían a las cláusulas de recepción y/o transformación, declarativas, de remisión, de interpretación y de jerarquía. 
Por cláusulas de recepción y/o transformación entendemos aquellas que admiten los efectos del derecho internacional, independientemente de si se requieren o no actos de transformación. Así las cosas, dentro de estas cláusulas encontramos dos categorías. Una primera que otorga los efectos jurídicos dentro de nuestro sistema normativo en el entretanto que haya un proceso de incorporación o transformación de la norma internacional y otra que, simplemente, admite efectos jurídicos directos 5 . Un ejemplo de estas es el artículo $9^{\circ}$ de la Carta que fundamenta las relaciones exteriores del Estado -entre otras cosas- en los principios generales del Derecho Internacional.

En cambio, las cláusulas declarativas son aquellas que simplemente ofrecen una explicación sobre cuál es la posición del Estado colombiano respecto de la comunidad y el ordenamiento jurídico internacional ${ }^{6}$. Ejemplos de ellas son los artículos 226 y 227 que promueven la internacionalización de las relaciones políticas del Estado y la integración económica.

Las cláusulas de remisión las hemos comprendido como todas aquellas normas constitucionales que nos refieren directamente al ordenamiento constitucional para entenderlas y desarrollarlas7. Vemos el caso del artículo 44 de nuestra Constitución que amplía la protección a niños, niñas y adolescentes conforme al Derecho Internacional.

Por su parte, las cláusulas de interpretación son, no las que nos remiten a otra norma, sino que, por el contrario, nos dicen que la interpretación de la norma constitucional debe hacerse a la luz del derecho internacional ${ }^{8}$. Este es el caso del parágrafo segundo del artículo 93 que establece la necesidad de interpretar los derechos y deberes consagrados de la Carta a la luz de los compromisos internacionales.

Finalmente, las cláusulas de jerarquía son aquellas que en efecto nos ofrecen luces sobre el lugar que ocupan las normas internacionales dentro de nuestro ordenamiento $y$, en ese sentido, permiten resolver eventuales conflictos normativos ${ }^{9}$. En este caso, el parágrafo primero del artículo 93 de la Carta, al reconocer la prevalencia de los tratados que consagran derechos humanos y prohíben su limitación en los estados de excepción, nos ofrece un claro ejemplo de este tipo de cláusulas.

\footnotetext{
5 RIVAS (2017a), pp. 378-381.

6 Rivas (2017a), pp. 378-381.

7 Rivas (2017a), pp. 378-381.

8 Rivas (2017a), pp. 378-381.

9 RIVAS (2017a), pp. 378-381.
} 


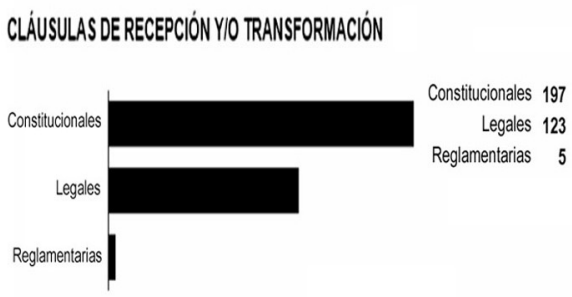

\section{CLAUSULAS DE REMISION}

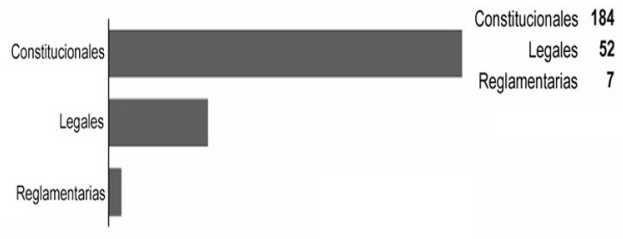

\section{CLÁUSULAS DE INTERPRETACIÓN}
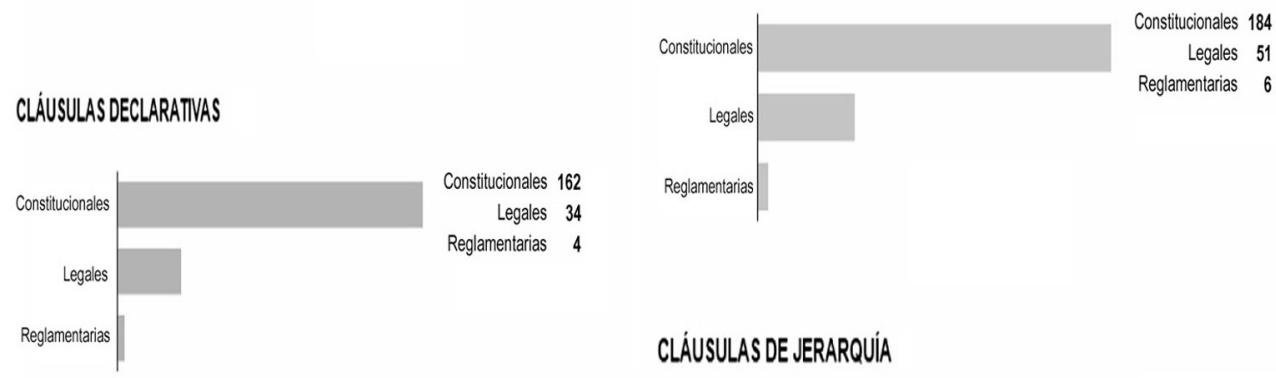

\section{CLÁUSULAS DE JERARQUIÁA}

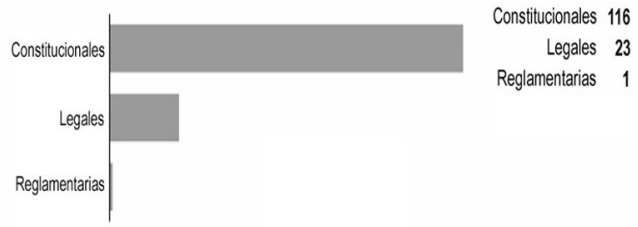

En la mayoría de los casos, la norma jurídica que se utilizaba para articular la norma internacional era una norma de naturaleza constitucional, como es el artículo $9^{\circ}$ sobre las relaciones exteriores de Estado y los principios del derecho internacional, o el artículo 227 sobre la integración económica, social y política de las naciones.

Tras estos primeros resultados meramente cuantitativos que, no obstante, pudieron confirmar varias de nuestras intuiciones, el equipo se dedicó al análisis de fondo de la jurisprudencia con el objeto de responder a las preguntas enlistadas en el apartado anterior. Como fruto de dicho trabajo resultaron diez documentos de análisis, cada uno de los cuales detalla los resultados de la segunda fase de investigación.

A continuación, presentaremos de forma sucinta las conclusiones generales a las que pudimos llegar tras la lectura transversal de tales documentos. Con base en éstas, apuntaremos algunas preocupaciones y proyectaremos algunos pronósticos. 


\section{LA LECTURA TRANSVERSAL DE LA JURISPRUDENCIA CONSTITUCIONAL SOBRE DERECHO INTERNACIONAL}

En una sola frase podemos resumir la conclusión general de este trabajo: en la jurisprudencia de la Corte Constitucional nada está claro. No es posible identificar por tanto un modelo teórico sobre la relación entre el derecho interno y el derecho internacional. Veamos esto según cada uno de los temas que abordamos.

En materia de Derecho Internacional de los Derechos Humanos, existe la creencia generalizada de que todo está resuelto cuando se trata de la relación del orden nacional con el orden internacional. Esta investigación arroja una conclusión muy distinta: casi todo está por decidirse.

Si bien la Corte ha insistido en la pertenencia de los tratados de derechos humanos al bloque de constitucionalidad, con fundamento principalmente en el artículo 93 de la Constitución Política, no hay claridad en los criterios para determinar cuándo los tratados ingresen al bloque stricto ${ }^{10}$ o lato sensu ${ }^{11}$. Esta determinación no es de poca importancia: de ésta depende nada menos que considerar normas de derecho internacional como parámetro de constitucionalidad

10 La Corte Constitucional de Colombia se ha pronunciado expresamente en sentencia C-540 del 12 de julio de 2012 sobre la pertenencia de tres tratados de derechos humanos al bloque stricto sensu, estos son: (i) la Declaración Universal de los Derechos Humanos, 1948, (ii) el Pacto Internacional de Derechos Civiles y Políticos, 1966 y (iii) la Convención Americana sobre Derechos Humanos, 1969. Al respecto ver: Corte Constitucional de Colombia, Sentencia C-540, del 12 de julio de 2012.

11 Respecto a esta distinción aparente, se puede ver Corte Constitucional de Colombia, Sentencia C-307 del 29, de abril de 2009; Corte Constitucional de Colombia, Sentencia C-853, del 25 de noviembre de 2009; Corte Constitucional de Colombia, Sentencia T-937 del 14 de diciembre de 2009; Corte Constitucional de Colombia, Sentencia T-968, del 18 de diciembre de 2009 y SU-254 del 24 de abril de 2013; Corte Constitucional de Colombia, Sentencia C-269, del 2 de mayo de 2014.

Sin embargo, la Corte ha tratado de manera indistinta ambas categorías en un gran número de sus providencias. Ver, entre otras, Corte Constitucional de Colombia, Sentencia C-070, del 12 de febrero de 2009; Corte Constitucional de Colombia, Sentencia C-135 del 25 de febrero 2009; Corte Constitucional de Colombia, Sentencia C-146 del 12 de marzo de 2009; Corte Constitucional de Colombia, Sentencia C-175 del 18 de marzo de 2009; Corte Constitucional de Colombia, Sentencia C-228 del 30 de marzo de 2009; Corte Constitucional de Colombia, Sentencia C-240 del 1 de abril de 2009; Corte Constitucional de Colombia, Sentencia C-288 del 21 de abril de 2009; Corte Constitucional de Colombia, Sentencia C-349 del 20 de mayo de 2009, Corte Constitucional de Colombia, Sentencia SU-913 del 11 de diciembre de 2009; Corte Constitucional de Colombia, Sentencia C-521 del 4 de agosto de 2009; Corte Constitucional de Colombia, Sentencia C-936 del 23 de noviembre de 2010; Corte Constitucional de Colombia, Sentencia C-366 del 11 de mayo de 2011; Corte Constitucional de Colombia, Sentencia T-137 del 1 de marzo de 2012; Corte Constitucional de Colombia, Sentencia SU-195 del 12 de marzo de 2012; Corte Constitucional de Colombia, Sentencia C-579 del 28 de agosto de 2013; Corte Constitucional de Colombia, Sentencia T-434 del 3 de julio de 2014; Corte Constitucional de Colombia, Sentencia T-256 del 5 de mayo de 2015. 
o como herramientas interpretativas. Por su parte, en relación con la jerarquía de normas internacionales referentes a derechos humanos diferentes a las convencionales, la Corte usa en sus sentencias principalmente jurisprudencia de tribunales internacionales, en especial de la Corte IDH, sin pronunciarse claramente sobre su jerarquía o fuerza vinculante en el derecho interno ${ }^{12}$. Y cuando se trata de principios generales en esta materia, costumbre internacional o jurisprudencia internacional, la Corte no asume una postura definitiva ${ }^{13}$.

Por el contrario, la postura de la Corte respecto del Derecho Internacional Humanitario parece más definida. En general, se asume que todas las normas de Derecho Internacional Humanitario son costumbre internacional, sin importar en qué instrumento se encuentren contenidas ${ }^{14}$. En consecuencia, y a la luz de los mandatos constitucionales, esas normas tienen efectos directos y son parámetro de constitucionalidad ${ }^{15}$. Ahora bien, aunque se ha determinado la pertenencia de las normas de DIH al bloque de constitucionalidad, la oscuridad en la jurisprudencia de la Corte respecto a este tema, se ve en el reconocimiento de ciertas normas de DIH como normas de ius $\operatorname{cogens}^{16}$, sin evidenciar claramente

12 Tal es el caso de sentencias como Corte Constitucional de Colombia, Sentencia T-950 del 20 de febrero de 2009; Corte Constitucional de Colombia, Sentencia C-288 del 30 de marzo de 2009; Corte Constitucional de Colombia, Sentencia C-156 del 9 de marzo de 2011, Corte Constitucional de Colombia, Sentencia T-908 del 1 de diciembre 2011; Corte Constitucional de Colombia, Sentencia T-035 del 3 de febrero de 2011; Corte Constitucional de Colombia, Sentencia T-119 del 3 de marzo de 2014 y Corte Constitucional de Colombia, Sentencia T-002 del 15 de enero de 2015, entre otras.

13 Con relación a esa indeterminación se puede ver en el caso de los principios generales del derecho internacional, las sentencias Corte Constitucional de Colombia, Sentencia C-438 del 10 de julio de 2013 y Corte Constitucional de Colombia, Sentencia T-824 del 5 de noviembre de 2014. En el caso de la costumbre internacional, ver Corte Constitucional de Colombia, Sentencia C-269 del 2 de mayo de 2014.

14 Cfr. Corte Constitucional de Colombia, Sentencia C-225 del 18 de mayo de 1995,; Corte Constitucional de Colombia, Sentencia C-191 del 6 de mayo de 1998; Corte Constitucional de Colombia, Sentencia C-894 del 2 de diciembre de 1999; Corte Constitucional de Colombia, Sentencia C-1189 del 13 de septiembre de 2000; Corte Constitucional de Colombia, Sentencia T-1017 del 9 de agosto de 2000 y Corte Constitucional de Colombia, Sentencia C-177 del 14 de febrero de 2001.

15 Tal y como lo determina la Corte Constitucional de Colombia en sentencias como Corte Constitucional de Colombia, Sentencia C-370 del 18 de mayo de 2006.

16 Incluso en la primera etapa de jurisprudencia de la Corte Constitucional de Colombia, se determinó que todas las normas de DIH eran normas de ius cogens, tal y como se aprecia en una de las últimas sentencias de esa etapa, Corte Constitucional de Colombia, Sentencia C-127 del 22 de febrero de 2006. Sin embargo, cabe anotar que posteriormente, desde la sentencia Corte Constitucional de Colombia, Sentencia C-291 del 25 de abril de 2007, hasta sentencias como Corte Constitucional de Colombia, Sentencia C-084 del 24 de febrero de 2016, la Corte ha matizado su posición en la materia, reconociendo que sólo algunas de las normas del DIH pertenecen a la categoría del Ius Cogens. 
los criterios de determinación, ni la posición jerárquica otorgada en el derecho interno a normas de esta naturaleza, aunque en su más reciente jurisprudencia, la Corte les ha reconocido valor supraconstitucional ${ }^{17}$.

Tratándose del Derecho Penal Internacional la confusión es abrumadora. Por un lado, se parte de una concepción dualista de la relación entre el DPI -en especial el Estatuto de Roma-, y el derecho interno, en el entendido de que sus normas tienen ámbitos de aplicación completamente diferenciados. Sin embargo, cuando se trata de la jerarquía del Estatuto de Roma, este instrumento ha sido fragmentado, incluyendo algunas de sus normas en el bloque de constitucionalidad -y por lo tanto otorgándoles un rango constitucional-, y dejando las demás sin jerarquización precisamente por su carácter ajeno al derecho interno ${ }^{18}$. Respecto de las demás normas de Derecho Penal Internacional, la lectura tampoco es clara, menos aún, teniendo en cuenta que la Corte ha apuntado el carácter de ius cogens de algunas de estas normas (e incluso algunas del Estatuto) y de su jurisprudencia no queda claro el rango en el derecho interno de normas de esta naturaleza: si es constitucional o supraconstitucional ${ }^{19}$. En cualquier caso, la Corte no aclara las consecuencias de asumir una u otra postura.

Toda esta confusión respecto de las normas de derechos humanos, derecho humanitario y derecho penal se hace evidente cuando se estudia el asunto de la justicia transicional en la jurisprudencia constitucional. Como pudimos ver, ante la inexistencia de instrumentos internacionales especializados y vinculantes sobre esta materia, la Corte echa mano, a la vez, de diversas y disímiles fuentes, a veces sin acudir a la lex specialis de la materia a estudiar ${ }^{20}$, y su discurso en torno a las fuentes varía según el tema y el contexto en el cual se inserte el tema

17 Tal y como se puede apreciar en el obiter dicta de la sentencia de la sentencia Corte Constitucional de Colombia, Sentencia C-269 del 2 de mayo de 2014 de la Corte Constitucional de Colombia.

18 Esta falta de determinación de la jerarquía se puede apreciar en sentencias como Corte Constitucional de Colombia, Sentencia C-240 del 1 de abril de 2009 de la Corte Constitucional de Colombia.

19 Así por ejemplo, en sentencias como Corte Constitucional de Colombia, Sentencia C-291 del 25 de abril de 2007 de la Corte Constitucional de Colombia, reconoce el artículo $8^{\circ}$ del Estatuto de Roma como norma de Ius Cogens, y por tanto, una naturaleza supraconstitucional. En cambio, en sentencias como Corte Constitucional de Colombia, Sentencia C-936 del 23 de noviembre de 2010 que habla sobre las normas del Estatuto que desarrollan los derechos de las víctimas les reconoce únicamente rango constitucional.

20 Esto se evidencia en la baja cantidad de veces que la Corte acude a normas de DIH, tratándose nuestro contexto de una transición de conflicto armado a la paz. Al respecto se puede ver cómo en el $49 \%$ de los casos en los que la Corte Constitucional ha abordado temas de justicia transicional, la Corporación ha omitido acudir al derecho propio de los conflictos y, por el contrario, se ha preocupado por atender las 
que se analiza. Es importante resaltar que en este tema se evidenció un avance importante en el uso de la figura del margen de apreciación en la solución de conflictos normativos ${ }^{21}$, que como veremos más adelante es una de las figuras que consideramos debe ser fortalecida en el marco de estas discusiones.

Del análisis de los temas anteriores, surgió en general una preocupación con respecto a la concepción que tiene la Corte y la aplicación del concepto de normas de ius cogens. Por un lado, su jurisprudencia fluctúa entre considerarlas normas de rango constitucional o supraconstitucional, generando inseguridad sobre las consecuencias que tendría un eventual conflicto entre normas de esta naturaleza y normas constitucionales ${ }^{22}$. Por otro lado, no se evidencian en la jurisprudencia los parámetros o criterios utilizados por la Corte para establecer que una norma tenga esta naturaleza; por ejemplo, la Corte pasó de decir que todas las normas de DIH eran normas de ius cogens, a decir que solo algunas lo eran, sin explicar las razones que sustentaran dicho cambio ${ }^{23}$.

En cuanto al tema del Derecho Internacional del Medio Ambiente, la situación tampoco es clara. Si bien la Corte ha asumido que la ley aprobatoria de tratado sobre medio ambiente es una ley de transformación, su jurisprudencia vacila cuando se trata de deducir de ello la naturaleza legal del tratado o no ${ }^{24}$. Pese a esto, la jurisprudencia ha dejado claro que, en ningún momento, las normas

disposiciones de la Convención Americana sobre Derechos Humanos y el Pacto Internacional de Derechos Civiles y Políticos.

21 Alrededor del 87\% de los casos en los que la Corte Constitucional de Colombia ha atendido el tema de la justicia transicional ha empleado de alguna manera el concepto de margen nacional de apreciación, como lo sucedido en el controversial caso de Corte Constitucional de Colombia, Sentencia C-579 del 28 de agosto de 2013 en la que la Corte utilizó el concepto para avalar la posibilidad de conceder amnistías e indultos a quienes no fuesen considerados responsables de graves crímenes de guerra y delitos de lesa humanidad. Al respecto ver Acosta y Espitia (2017), pp. 497-556.

22 Cfr. Nota 21.

23 Tal contraste se puede ver en la diferencia entre las sentencias previas al año 2006 y las posteriores al año 2007. Cfr. Nota 18.

${ }^{24}$ La naturaleza de la ley aprobatoria como ley de transformación se puede apreciar en sentencias de la Corte Constitucional de Colombia como Corte Constitucional de Colombia, Sentencia C-519 del 21 de noviembre de 1994; Corte Constitucional de Colombia, Sentencia C-671 del 28 de junio de 2001 y Corte Constitucional de Colombia, Sentencia C-703 del 6 de septiembre de 2010. Sin embargo, desde sentencias fundacionales como Corte Constitucional de Colombia, Sentencia T-411 del 17 de junio de 1992 y en otras más actuales como Corte Constitucional de Colombia, Sentencia C-035 del 8 de febrero de 2016 se puede ver que la Corte no logra determinar el rango de este tipo de normas internacionales al no poder aplicar por analogía las "reglas" utilizadas en los casos del DIDH y el DIH. 
nacionales en la materia pueden ser confrontadas frente a las obligaciones de los tratados al respecto. En cuanto a la costumbre ambiental no hay pronunciamientos y en relación con los principios generales se asume que estos han sido recopilados en los tratados que han sido ratificados ${ }^{25}$, lo mismo se predica respecto del soft law ${ }^{26}$. Quizás la única idea constante de la Corte en esta materia es que la función principal del derecho internacional ambiental es la de servir como herramienta interpretativa, reduciendo así el alcance de las obligaciones internacionales en la materia ${ }^{27}$.

Tratándose de los asuntos territoriales la confusión es la constante. La Corte insiste en afirmar que dichos tratados hacen parte del Bloque en sentido estricto $^{28}$. Pese a esto, de la lectura transversal de su último caso sobre este asunto (Sentencia C-269 de 2014) podría inferirse que dichos tratados tienen un cierto halo supraconstitucional toda vez que ninguna norma interna, ni siquiera una norma constitucional, puede contradecirlos. En otras palabras, no queda clara la jerarquía de dichas normas o los efectos de asumir una u otra respuesta en torno a este asunto. En cuanto a la jerarquía de las demás fuentes internacionales sobre asuntos territoriales, la Corte afirma que no sirven para reformar los límites del Estado, pero no les concede rango normativo alguno.

Cuando se estudia el tema del derecho internacional de la inversión extranjera, y en general en cuanto al derecho económico internacional, encontramos una respuesta clara que, no obstante, deja un vacío significativo. Las normas internacionales en la materia, contenidas, mayoritaria pero no exclusivamente, en tratados internacionales, adquieren naturaleza legal dentro de nuestro orde-

25 Corte Constitucional de Colombia, Sentencia C-1189 del 13 de septiembre de 2000.

26 Corte Constitucional de Colombia, Sentencia C-528 del 24 de noviembre de 1994; Corte Constitucional de Colombia, Sentencia C-595 del 27 de julio de 2010; Corte Constitucional de Colombia, Sentencia C-632 del 24 de agosto de 2011.

27 Tal continuidad en el razonamiento de la Corte Constitucional de Colombia se puede evidenciar a lo largo de su línea jurisprudencial en sentencias como Corte Constitucional de Colombia, Sentencia T-411 del 17 de noviembre de 1992, Corte Constitucional de Colombia, Sentencia C-058 del 17 de febrero de 1994; Corte Constitucional de Colombia, Sentencia T-299 del 3 de abril de 2008 y Corte Constitucional de Colombia, Sentencia C-703 del 6 de septiembre de 2010.

28 Corte Constitucional de Colombia, Sentencia C-191 del 6 de mayo de 1998; Corte Constitucional de Colombia, Sentencia C-400 del 10 de agosto de 1998 y Corte Constitucional de Colombia, Sentencia C-1022 del 16 de diciembre de 1999. 
namiento ${ }^{29}$. A la luz de esta idea el juez constitucional apunta que en caso de conflictos normativos debe procurarse una interpretación conforme, pero, ¿qué hacer cuando ella es imposible? Y, más aún, ¿cuándo la imposibilidad de dicha armonización pone en riesgo la protección de bienes e intereses constitucionales?30 Este silencio ante un tema cada vez más importante para el futuro del país es muy preocupante. Ahora bien, pese a la respuesta clara de la Corte respecto a la naturaleza legal de dichas normas, como pudimos ver, en algunas ocasiones las usa de forma complementaria como parámetros de control de constitucionalidad de las normas nacionales e incluso de otras normas internacionales ${ }^{31}$.

Vistas a la luz de estas conclusiones, analizando tema por tema, podemos ver cuán imposible es afirmar la prevalencia de un modelo teórico u otro cuando se trata de explicar la relación entre el derecho internacional y el derecho interno. Pese a que de forma reiterada se ha afirmado que dicha relación se construye a partir de la idea de un monismo moderado, como pudimos ver, esta conclusión tiene dos importantes problemas. La primera es que la idea de monismo moderado usada por la Corte ha sido manipulada. La versión de nuestra jurisprudencia es una versión criolla que tergiversa las ideas originales de Verdross para adaptar sus premisas a una lectura bastante confusa ${ }^{32}$. La segunda es que, según lo estudiado, no existe respuesta única, o mejor, no hay respuesta clara, sobre el lugar que ocupan las normas internacionales en nuestro sistema normativo, ni sobre las consecuencias de asignarles un lugar u otro, por lo que mantener la idea de un único sistema, perfectamente articulado y regido por el principio jerárquico, resulta imposible.

Justamente esta situación, y, en general, la falta de respuestas claras nos permite trazar unas conclusiones transversales. Veamos.

29 Evidenciado en sentencias como Corte Constitucional de Colombia, Sentencia C-750 del 24 de julio de 2008; Corte Constitucional de Colombia, Sentencia C-309 del 3 de mayo de 2007; Corte Constitucional de Colombia, Sentencia C-031 del 28 de enero de 2009; Corte Constitucional de Colombia, Sentencia C-157 del 6 de abril de 2016 y Corte Constitucional de Colombia, Sentencia C-184 del 14 de abril de 2016.

30 Una eventual respuesta empírica a estas preguntas sería la de moldear el ordenamiento jurídico hasta que fuesen compatibles como sucedió con la reforma del artículo 58 de la Constitución nacional de Colombia en la década de los 90. Al respecto ver: Rivas (2017b), pp. 627-660.

31 Es el caso de lo sucedido en sentencias como la C-961 del 2006 en la que la utilización de las normas internacionales en la materia fue hecha evidentemente como parámetro de constitucionalidad complementario, hasta tal punto que motivó al magistrado Jaime Araújo Rentería a aclarar su voto en tal sentido.

32 Huertas (2016), pp. 197-234. 


\section{De anacronismos y vaticinios}

Como acabamos de señalar, luego del análisis realizado por nuestro equipo de trabajo, podemos corroborar el principal instinto que motivó el proyecto de investigación: la Corte Constitucional no tiene del todo claro cómo se teje la relación entre el derecho internacional y el derecho interno. Pese a su esfuerzo por lograr una relación armónica entre los dos ordenamientos, el uso confuso de los principios que orientan las viejas teorías que intentaban explicar este asunto, la insistencia respecto de la idea de jerarquías absolutas y, pese a ello, la falta de claridad sobre el lugar que ocupan la mayoría de las normas internacionales en el ordenamiento nacional, así como la ausencia de reglas claras sobre solución de conflictos entre unas y otras, son prueba de que sobre este tema aún hay mucho por decir.

Quizás lo que más nos preocupa de este asunto es que el juez constitucional insista en servirse de los viejos modelos teóricos, útiles otrora para la vieja realidad iusinternacionalista, pero completamente obsoletos ante el nuevo contexto. Es a esto a lo que le llamamos anacronismos. Desde nuestro punto de vista, de esa terquedad resulta la lectura errada de varias cuestiones y la ausencia de respuestas útiles ante las crecientes dificultades. Veamos esto con un poco de detenimiento.

En primer lugar, el juez constitucional insiste en que el derecho internacional "se incorpora" en el derecho interno, dando a entender así que estamos en presencia de un único ordenamiento toda vez que, desde su lectura, el derecho internacional se transforma en norma nacional o, por lo menos, surte un trámite de incorporación. Esta lectura se sostiene principalmente respecto de los tratados internacionales, los cuales han ocupado de manera privilegiada la atención de la Corte, pues el juez constitucional cree que el trámite de autorización para la ratificación, previsto en la Constitución, tiene como resultado una transformación o incorporación de la norma internacional. Así mismo, podemos deducir esta idea general de 'único ordenamiento' cuando la Corte hace esfuerzos, confusos, pero esfuerzos al fin y al cabo, por determinar la jerarquía de las normas de origen internacional dentro de la llamada pirámide normativa.

¿Por qué entendemos lo anterior como una cuestión problemática? En síntesis, la lectura respecto del ordenamiento único y la cuestión de la incorporación parte de dos presupuestos errados. Primero, mezcla las premisas básicas de los dos modelos teóricos que tradicionalmente se han empleado para explicar las relaciones entre el derecho internacional y el derecho interno. Por una parte, como el monismo, se afirma que estamos en presencia de un único ordena- 
miento; pese a ello, como afirma el dualismo, se insiste en la idea de que la responsabilidad por el incumplimiento de una obligación internacional -ante la preferencia de una norma nacional-se regula, tan sólo, a la luz de las normas internacionales. Es decir, el mismo acto del Estado podría generar responsabilidad internacional, pero ser válido en el ámbito doméstico. Esta confusión es quizá el origen de gran parte de los vaivenes jurisprudenciales y de la ausencia de herramientas útiles al operador jurídico ante posibles conflictos normativos; la jurisprudencia padece una bipolaridad monista-dualista que le impide dar cuenta de soluciones claras.

Segundo, y quizás más importante, esta situación se origina en una lectura errada de las normas constitucionales. Por ejemplo, el juez constitucional ha entendido que el trámite previsto en la Constitución, para autorizar al Presidente de la República a ratificar tratados internacionales, erige a la norma internacional en ley de la República o por lo menos la ubica en la misma categoría de las leyes (salvo que trate asuntos relativos al Bloque). Como consecuencia de lo anterior, existe la idea generalizada de que dicha ley es la que da origen a la obligación internacional (premisa errada pues, como es sabido, la obligación sólo surge en el momento de la ratificación) o que la ley es la que "contiene" la obligación internacional, la que incorpora dicha obligación, en vez de comprenderla como el mero procedimiento previo y no vinculante que redunda en una mera autorización para la ratificación, por lo que no se trata de un acto de incorporación mediada por ley ni de un acto de transformación.

En ese mismo sentido, pese a la claridad de la norma constitucional en materia de principios o a la consecuencia evidente del silencio constitucional en torno a la costumbre, según la cual unos y otros tienen efectos directos, la Corte ha preferido las disquisiciones enrevesadas para intentar dotarlas de fuerza vinculante y de categoría normativa.

Tercero, la idea de ordenamiento único desconoce las características propias del ordenamiento internacional (variedad de fuentes, ausencia de jerarquías, creciente fragmentación, complejidad normativa e institucional) y sus abismales diferencias con el derecho interno, así como la dinámica propia de las relaciones internacionales.

Es esta confusión respecto de la necesidad de incorporación, y la idea de ordenamiento único que hay detrás, la que pone en aprietos al juez constitucional a la hora de responder en qué categoría normativa se ubican las normas internacionales y las consecuencias que de ello se desprenden para la solución 
de los conflictos normativos o para la construcción de los parámetros de control de constitucionalidad o de legalidad.

Esto nos trae justamente al segundo asunto: la cuestión de los conflictos normativos y la ausencia de herramientas útiles para que el operador jurídico sepa qué hacer a la hora de trabajar con normas internacionales. Como pudimos ver en los diferentes capítulos que conforman esta investigación, dado el fuerte arraigo de la idea de ordenamiento único y el consecuente valor de la jerarquía en este contexto, el juez constitucional insiste en la fórmula norma superior prevalece sobre norma inferior. Sin embargo, esta idea pone al propio juez constitucional contra las cuerdas explicando así el vaivén de la jurisprudencia.

Según quedó establecido, ni siquiera tratándose de las normas pertenecientes al bloque el juez ha definido de forma unívoca y predeterminada las consecuencias del reconocimiento de la naturaleza constitucional de algunas normas. Algunas veces son parámetros de control, otras tan sólo herramientas de interpretación, según se trate del bloque en sentido estricto o en sentido lato (aun cuando no quede claro cuándo ocurre una cosa y cuándo otra). Respecto de las demás normas internacionales, la respuesta es "depende... pero ni aun así". Es decir, todo depende del tipo de norma internacional de que se trate y de su contenido, pero ni siquiera esto es garantía, pues, en cualquier caso, ante un eventual conflicto normativo la respuesta del mal llamado monismo moderado de la Corte deja al operador jurídico ante la "espada de Damocles": debe respetar siempre el ordenamiento nacional, procurando no saltarse el internacional y en caso de que ello no sea posible ha de asumir las consecuencias de generar la responsabilidad internacional, pese a que esto le pueda costar a él, como funcionario, y al Estado, como responsable ante la comunidad internacional, serios dolores de cabeza, en especial dolores de naturaleza presupuestal.

Esta vaga "solución" nos deja, además, ante una pregunta aún más importante: si el Estado, llámese legislador, administrador o juez, puede descartar la norma internacional ante la imposibilidad de armonización, sin más, entonces ¿para qué los compromisos internacionales? O, si lo queremos leer desde la mirada constitucional y nacional, ¿̇ante la imposibilidad de armonizar las normas internacionales con las normas nacionales que buscan satisfacer las necesidades del país no queda otra salida más que asumir la responsabilidad internacional? En suma, ante uno u otro evento, ¿no tenemos otra opción más que cruzarnos de brazos y "pagar los platos rotos"?

La jurisprudencia constitucional no nos ofrece respuestas satisfactorias a estas preguntas, toda vez que no es clara respecto a la relación entre el derecho 
internacional y el derecho interno, pues, como vimos, su esfuerzo por dar luces en torno a este asunto redunda en vaivenes jurisprudenciales y ausencia de respuestas suficientes. Ello se debe, en gran parte, a su insistencia en el uso de varias ideas anacrónicas, pese a los importantes cambios que han experimentado los ordenamientos constitucionales y -por supuesto- el derecho internacional. Es justamente en este contexto donde se justifican algunos vaticinios.

El primero de ellos resulta obvio: la jurisprudencia constitucional en torno a este asunto ha de renovarse. Ante una nueva realidad, nuevas lecturas. La primera tarea que debe emprenderse es la de reconocer que los viejos modelos teóricos son insuficientes. En otras palabras, ante una realidad plural y compleja, monismo y dualismo -en cualquiera de sus vertientes- han de pasar a mejor vida.

De la mano con esto viene una tarea titánica: construir un nuevo modelo que responda a la nueva realidad y que ofrezca salidas útiles a los retos que trae consigo. Superar estos retos está, principalmente, en manos del juez constitucional, quien debe ser consciente de la importancia de dotar de coherencia sistémica a la jurisprudencia relacionada con normas internacionales, para desde allí perfilar las características y reglas básicas de la nueva relación entre el derecho internacional y el derecho interno. Ahora bien, quienes trabajamos desde la academia tenemos una responsabilidad inmensa en torno a este asunto: debemos proponer lecturas útiles de esta relación y herramientas adecuadas para enfrentar los desafíos que ésta supone. Este diagnóstico es una primera apuesta hacia ese camino.

En este contexto, nos atrevemos a lanzar un tercer pronóstico: la idea de jerarquía no puede regir la relación entre los dos ordenamientos. Desde nuestro punto de vista, hablar de "incorporaciones" o de "transformaciones" no tiene sentido a la luz de las normas constitucionales, mucho menos frente a la actual dinámica del ordenamiento internacional. En este sentido, creemos que debe abandonarse la idea de un único ordenamiento y, con ella, los intentos por encajar las normas internacionales en las categorías normativas domésticas. $\mathrm{Al}$ respecto, bastaría con reconocer que, una vez que surge la obligación internacional, cualquiera que sea su fuente, ésta tiene efectos directos (independientemente de si luego, algunas de ellas, requieren ciertos desarrollos legales). Ello evitaría los entuertos jurisprudenciales respecto de la categoría normativa sin que se sacrifique el principio de legalidad o el llamado pacta sunct servanda.

Finalmente, y como consecuencia de lo anterior, ante la ausencia de jerarquía surge la necesidad de pensar en nuevas herramientas de acoplamiento. Al respecto resulta fundamental organizar las ideas en torno a dos asuntos diferentes. En primer lugar, reconocidos los efectos directos de las obligaciones internacionales, ¿qué papel 
tienen estas en el escenario doméstico?, ¿acaso se erigen como mandatos directos de toda actividad estatal? (la respuesta parece obvia, pero ya vimos de la jurisprudencia constitucional que no está del todo claro), ¿son parámetros de control constitucional y/o legal de las normas nacionales?, ¿fungen como meros criterios de interpretación?, ¿de ellas se desprenden obligaciones directas de adaptación?

En segunda instancia, y quizás de forma prioritaria, debemos responder una pregunta clave: ¿cómo se resuelven los conflictos entre normas nacionales y normas internacionales? Ante la ausencia de criterios jerárquicos resulta necesario debatir cuáles son los principios o las reglas que habrán de regir la relación entre los dos ordenamientos y en este contexto pareciera que la única salida son los llamados mecanismos de acoplamiento. Sin embargo, este es un terreno aún por explorar. ¿Qué son los mecanismos de acoplamiento?, ¿cuál es su fundamento, su naturaleza y alcance?, ¿cuáles son las consecuencias de su uso?

Algunas palabras claves se nos vienen a la mente: identidad constitucional, subsidiariedad, margen de apreciación, interpretación conforme, ponderación, integración sistémica. No obstante, en el escenario latinoamericano, y qué decir del colombiano, estos son asuntos muy poco explorados. Por ello, el gran reto entre manos es trabajar en torno a todas estas cuestiones con miras a ofrecerle a los operadores jurídicos nacionales, pero también internacionales, herramientas útiles en la construcción de la nueva relación entre el derecho internacional y el derecho interno, así como salidas a las dificultades que ella implica.

Como se observa, hay un mucho trabajo por delante. Esperamos que este primer diagnóstico parcial permita crear conciencia sobre la urgencia de repensar este importante tema e inspire nuevas investigaciones y propuestas ante los desafíos que trae consigo la creciente interdependencia entre el derecho internacional y el derecho interno. ¡Confiamos en que las nuevas iniciativas no se hagan esperar!

\section{BIBLIOGRAFÍA CITADA}

Acosta Alvarado, Paola Andrea (2016). "Zombis vs. Frankenstein: Sobre las relaciones entre el Derecho Internacional y el Derecho Interno", en Revista Estudios Constitucionales (Año 14, No 1), pp. 15-60.

Acosta Alvarado, Paola Andrea; Acosta-López, Juana Inés; Rivas-Ramírez, Daniel (2017). De anacronismos y vaticinios. Diagnóstico sobre las relaciones entre el derecho internacional y el derecho interno en Latinoamérica (Bogotá, Universidad Externado de Colombia). 
Acosta-López, Juana Inés y Espitia Murcia, Cindy Vanessa (2017) "La justicia transicional a la luz del derecho internacional: la perspectiva de la Corte Constitucional colombiana”, en A.A.V.V. De anacronismos y vaticinios: diagnóstico de las relaciones entre el derecho internacional y el derecho interno en Latinoamérica (Bogotá, Universidad Externado de Colombia), pp. 497-556 HuERTAS, Julián Eduardo (2016). "Monismo moderado colombiano: examen a la teoría oficial de la Corte Constitucional desde la obra de Alfred Verdross", en Revista Vniversitas (Año 16, No 132), pp. 197-234.

Rivas Ramírez, Daniel (2017a). "Análisis de resultados de la primera fase del proyecto", en A.A.V.V., De anacronismos y vaticinios: diagnóstico de las relaciones entre el derecho internacional y el derecho interno en Latinoamérica (Bogotá, Universidad Externado de Colombia), pp. 371-382.

Rivas Ramírez, Daniel (2017b). "El derecho internacional de las inversiones, otro de los desaires de la jurisprudencia constitucional colombiana", en A.A.V.V., De anacronismos y vaticinios: diagnóstico de las relaciones entre el derecho internacional y el derecho interno en Latinoamérica (Bogotá, Universidad Externado de Colombia), pp. 627-660.

\section{JURISPRUDENCIA CITADA}

\section{Sentencias de tutela}

José Felipe Tello Varón con. Alcaldía Municipal de Granada (1992). Corte Constitucional de Colombia 17 de junio de 1992 (Acción de Tutela). Disponible en relatoría de la Corte Constitucional como sentencia T-411 de 1992, [fecha de consulta: 17 de septiembre de 2017]. [Disponible en: http://www. corteconstitucional.gov.co/relatoria/1992/t-411-92.htm].

Ana Elisa Ramírez e hijas con. Colegio Departamental Nocturno Jacinto Vásquez Ochoa (2000). Corte Constitucional de Colombia 9 de agosto de 2000 (Acción de Tutela). Disponible en relatoría de la Corte Constitucional como sentencia T-1017 de 2000, [fecha de consulta: 17 de septiembre de 2017]. [Disponible en: http://www.corteconstitucional.gov.co/relatoria/2000/T-1017-00.htm].

Luis Hernando Ospina, Marleny Rodriguez Hortúa e hijos con. Codensa S.A. E.S.P. (2008). Corte Constitucional de Colombia 3 de abril de 2008 (Acción de Tutela). Disponible en relatoría de la Corte Constitucional como sentencia T-299 del 2008, [fecha de consulta: 17 de septiembre de 2017]. Disponible en: http://www.corteconstitucional.gov.co/relatoria/2008/T-299-08.htm]. 
Jovánny Valencia Gómez contra Instituto de Seguros Sociales (2009). Corte Constitucional de Colombia 14 de diciembre de 2009 (Acción de Tutela). Disponible en relatoría de la Corte Constitucional como sentencia T-937 del 2009, [fecha de consulta: 17 de septiembre de 2017]. [Disponible en: http:// www.corteconstitucional.gov.co/relatoria/2009/t-937-09.htm].

María Lilia Rendón Muñoz con. Instituto de Seguros Sociales - Seccional Caldas (2009). Corte Constitucional de Colombia 16 de diciembre de 2009 (Acción de Tutela). Disponible en relatoría de la Corte Contstitucional como sentencia T-950 del 2009, [fecha de consulta: 17 de septiembre de 2017]. [Disponible en: http://www.corteconstitucional.gov.co/relatoria/2009/t-950-09.htm].

Sarai contra Juzgado Décimo de Familia de Cali (2009). Corte Constitucional de Colombia 18 de diciembre de 2009 (Acción de Tutela). Disponible en relatoría de la Corte Constitucional como sentencia T-968 del 2009, [fecha de consulta: 17 de septiembre de 2017]. [Disponible en: http://www.corteconstitucional.gov.co/relatoria/2009/T-968-09.htm].

Hernán Figueroa Pinilla contra Saludcoop EPS y Secretaría de Salud Departamental de Santander (2011). Corte Constitucional de Colombia 3 de febrero de 2011 (Acción de Tutela). Disponible en relatoría de la Corte Constitucional como sentencia T-035 del 2011, [fecha de consulta: 17 de septiembre de 2017]. [Disponible en: http://www.corteconstitucional.gov. co/relatoria/2011/T-035-11.htm].

Cristian José Polo Rodríguez contra Escuela Superior Normal de Santa Teresita de Lorica (2011). Corte Constitucional de Colombia 1 de diciembre de 2011 (Acción de Tutela). Disponible en relatoría de la Corte Constitucional como sentencia T-908 del 2011, [fecha de consulta: 17 de septiembre de 2017]. [Disponible en: http://www.corteconstitucional.gov.co/relatoria/2011/T-908-11.htm].

Jairo Holguin Rincón, Emidio José Orozco Pérez y Ana Ledy Oliveros Valdés contra Porvenir S.A., Orozco con. Protección S.A. y Salud Total EPS (2012). Corte Constitucional de Colombia 1 marzo de 2012 (Acciones de tutela interpuestas separadamente). Disponible en relatoría de la Corte como sentencia T-137 del 2012, [fecha de consulta: 17 de septiembre de 2017]. [Disponible en: http://www.corteconstitucional.gov.co/relatoria/2012/T-137-12.htm].

Jimmy Hernando León Herrera con. ICETEX, ICFES, Ministerio de Educación Nacional y Departamento Administrativo de la Función Pública. Corte Constitucional de Colombia 3 de marzo del 2014. (Acción de Tutela) Disponible en relatoría de la Corte Constitucional como sentencia T-119 del 2014, 
[fecha de consulta: 17 de septiembre de 2017]. [Disponible en: http://www. corteconstitucional.gov.co/relatoria/2014/T-119-14.htm].

Angélica Maria Gaona Galindo en calidad de Defensora Regional del Magdalena Medio (a favor de Aurora Hernández e hijas) con. Dirección Nacional de la Fiscalia, Dirección Seccional de la Fiscaía el Circuito de Bucaramanga, Coordinación de la Fiscalia de Barrancabermeja y Cafesalud EPS (2014). Corte Constitucional de Colombia 3 de julio de 2014 (Acción de tutela). Disponible en relatoría de la Corte Constitucional como sentencia T-434 del 2014, [fecha de consulta: 17 de septiembre de 2017]. [Disponible en: http://www. corteconstitucional.gov.co/relatoria/2014/T-434-14.htm].

Hernando Mendoza Mendoza con. Banco Agrario de Colombia S.A. (2014). Corte Constitucional de Colombia 5 de noviembre de 2014 (Acción de Tutela). Disponible en relatoría de la Corte Constitucional como sentencia T-824 del 2014, [fecha de consulta: 17 de septiembre de 2017]. [Disponible en: http://www.corteconstitucional.gov.co/RELATORIA/2014/T-824-14.htm]. Delia Fabregas de Serrano con. Colpensiones y Servicio Nacional de Aprendizaje SENA (2015). Corte Constitucional de Colombia 15 de enero de 2015 (Acción de Tutela). Disponible en relatoría de la Corte Constitucional como sentencia T-002 del 2015, [fecha de consulta: 17 de septiembre de 2017]. [Disponible en: http://www.corteconstitucional.gov.co/relatoria/2015/T-002-15.htm]. Comunidad ancestral de negros de los corregimientos de Patilla y Chancleta del municipio de Barrancas con. Carbones del Cerrejón Limited (2015). Corte Constitucional de Colombia 5 de mayo de 2015 (Acción de Tutela). Disponible en relatoría de la Corte Constitucional como sentencia T-256 del 2015, [fecha de consulta: 17 de septiembre de 2017]. [Disponible en: http:// www.corteconstitucional.gov.co/relatoria/2015/t-256-15.htm].

\section{Sentencias de Constitucionalidad ${ }^{33}$}

Alfonso Palma Capera con. Ley No 48 de 1993 (1994). Corte Constitucional de Colombia 17 de febrero de 1994. (Acción pública de inconstitucionalidad).

\footnotetext{
33 En atención a las políticas editoriales de la Revista, se ha ajustado la forma de citación a ellas. Es por ello que en cada una de las referencias aparecen como partes, la persona o entidad que inició la acción de inconstitucionalidad y la ley demandada. En el caso de las sentencias que versan sobre leyes aprobatorias de tratados internacionales, como partes del proceso se señalan, la Corte Constitucional y la ley que aprueba el tratado internacional.
} 
Disponible en relatoría de la Corte Constitucional como sentencia C-058 de 1994, [fecha de consulta: 17 de septiembre de 2017]. [Disponible en: http:// www.corteconstitucional.gov.co/relatoria/1994/C-058-94.htm].

Corte Constitucional de Colombia con. Ley No 162 de 1994 (1994). Corte Constitucional de Colombia 21 de noviembre de 1994 (Control previo de constitucionalidad de ley aprobatoria). Disponible en línea como sentencia C-519 de 1994, [fecha de consulta: 17 de septiembre de 2017]. [Disponible en: http://www.corteconstitucional.gov.co/relatoria/1994/C-519-94.htm].

Andrés Rodríguez Pizarro con. Ley No 99 de 1993 (1994). Corte Constitucional de Colombia 24 de noviembre de 1994 (Acción pública de inconstitucionalidad). Disponible en relatoría de la Corte Constitucional como sentencia C-528 de 1994, [fecha de consulta: 17 de septiembre de 2017].] [Disponible en: http://www.corteconstitucional.gov.co/relatoria/1994/C-528-94.htm].

Corte Constitucional de Colombia con. Ley No 171 de 1994 (1995). Corte Constitucional de Colombia 18 de mayo de 1995 (Control previo de constitucionalidad de ley aprobatoria). Disponible en relatoría de la Corte Constitucional como sentencia C-225 de 1995, [fecha de consulta: 17 de septiembre de 2017]. [Disponible en: http://www.corteconstitucional.gov. co/relatoria/1995/c-225-95.htm].

Danilo Devis Pereira con. Ley No 397 de 1997 (1998). Corte Constitucional de Colombia (1998), del 6 de mayo de 1998 (Acción pública de inconstitucionalidad). Disponible en relatoría de la Corte Constitucional como sentencia C-191 de 1998, [fecha de consulta: 17 de septiembre de 2017]. [Disponible en: http://www.corteconstitucional.gov.co/relatoria/1998/C-191-98.htm].

Germán Cavelier Gaviria y otro con. Ley No 446 de 1998 (1999). Corte Constitucional de Colombia 11 de agosto de 1999 (Acción pública de inconstitucionalidad). Disponible en relatoría de la Corte Constitucional como sentencia C-582 de 1999, [fecha de consulta: 17 de septiembre de 2017]. [Disponible en: http://www.corteconstitucional.gov.co/relatoria/1999/c-582-99.htm]. Marcela Tamayo Arango con. Ley No 488 de 1998 (1999). Corte Constitucional de Colombia 10 de noviembre de 1999 (Acción pública de inconstitucionalidad). Disponible en relatoría de la Corte Constitucional como sentencia C-894 de 1999, [fecha de consulta: 17 de septiembre de 2017]. [Disponible en: http://www.corteconstitucional.gov.co/relatoria/1999/C-894-99.htm].

Corte Constitucional de Colombia con. Ley No 539 de 1999 (1999). Corte Constitucional de Colombia 16 de diciembre de 1999 (Control previo de 
constitucionalidad de ley aprobatoria). Disponible en relatoría de la Corte Constitucional como sentencia C-1022 de 1999, [fecha de consulta: 17 de septiembre de 2017]. [Disponible en: http://www.corteconstitucional.gov. co/relatoria/1999/C-1022-99.htm].

Hernán José Jiménez Carvajal con. Código Penal (2000). Corte Constitucional de Colombia 13 de septiembre de 2000 (Acción pública de inconstitucionalidad). Disponible en relatoría de la Corte Constitucional como sentencia C-1189 de 2000, [fecha de consulta: 17 de septiembre de 2017]. [Disponible en: http://www.corteconstitucional.gov.co/relatoria/2000/c-1189-00.htm].

Marcela Adriana Rodríguez Gómez con. Ley No 589 del 2000 (2001). Corte Constitucional de Colombia 14 de febrero de 2001 (Acción pública de inconstitucionalidad). Disponible en relatoría de la Corte Constitucional como sentencia C-177 de 2001, [fecha de consulta: 17 de septiembre de 2017]. [Disponible en: http://www.corteconstitucional.gov.co/relatoria/2001/c-177-01.htm].

Corte Constitucional de Colombia con. Ley No 618 de 2000 (2001). Corte Constitucional de Colombia 28 de junio de 2001 (Control previo de constitucionalidad de ley aprobatoria). Disponible en relatoría de la Corte Constitucional como sentencia C-671 de 2001, [fecha de consulta: 17 de septiembre de 2017]. [Disponible en: http://www.corteconstitucional.gov. co/RELATORIA/2001/C-671-01.htm].

Gustavo Gallón Giraldo y otros con. Ley No 975 de 2005 (2006). Corte Constitucional de Colombia 18 de mayo de 2006 (Acción pública de inconstitucionalidad). Disponible en relatoría de la Corte Constitucional como sentencia C-370 de 2006, [fecha de consulta: 17 de septiembre de 2017]. [Disponible en: http:/www.corteconstitucional.gov.co/relatoria/2006/C-370-06.htm].

Jorge Enrique Arango con. Ley No 975 de 2005 (2006). Corte Constitucional de Colombia 22 de febrero de 2006 (Acción pública de inconstitucionalidad). Disponible en relatoría de la Corte Constitucional como sentencia C-127 de 2006, [fecha de consulta: 17 de septiembre de 2017]. Disponible en: http:// www.corteconstitucional.gov.co/relatoria/2006/C-127-06.htm].

Jorge Hernán Gil Echeverry con. Ley No 963 de 2005 (2006). Corte Constitucional de Colombia 22 de noviembre de 2006 (Acción pública de inconstitucionalidad). Disponible en relatoría de la Corte Constitucional como sentencia C-961 de 2006, [fecha de consulta: 17 de septiembre de 2017]. [Disponible en: http://www.corteconstitucional.gov.co/relatoria/2006/C-961-06.htm]. 
Alejandro Valencia Villa con. Ley No 599 de 2000 y Ley No 522 de 1999 (2007). Corte Constitucional de Colombia 25 de abril de 2007 (Acción pública de inconstitucionalidad). Disponible en relatoría de la Corte Constitucional como sentencia C-291 de 2007, [fecha de consulta: 17 de septiembre de 2017]. [Disponible en: http://www.corteconstitucional.gov.co/ relatoria/2007/c-291-07.htm].

Corte Constitucional de Colombia con. Ley No 1.069 de 2006 (2007). Corte Constitucional de Colombia 3 de mayo de 2007 (Control previo de constitucionalidad de ley aprobatoria). Disponible en relatoría de la Corte Constitucional como sentencia C-309 de 2007, [fecha de consulta: 17 de septiembre de 2017]. [Disponible en: http://www.corteconstitucional.gov. co/relatoria/2007/c-309-07.htm].

Corte Constitucional de Colombia con. Ley No 1.143 de 2007 (2008). Corte Constitucional de Colombia 24 de julio de 2008 (Control previo de constitucionalidad de ley aprobatoria). Disponible en relatoría de la Corte Constitucional como sentencia C-750 de 2008, [fecha de consulta: 17 de septiembre de 2017]. [Disponible en: http://www.corteconstitucional.gov. co/RELATORIA/2008/C-750-08.htm].

Corte Constitucional de Colombia con. Ley No 1.189 de 2008 (2009). Corte Constitucional de Colombia 28 de enero de 2009 (Control previo de constitucionalidad de ley aprobatoria). Disponible en relatoría de la Corte Constitucional como sentencia C-031 de 2009, [fecha de consulta: 17 de septiembre de 2017]. [Disponible en: http://www.corteconstitucional.gov. co/relatoria/2009/C-031-09.htm].

Corte Constitucional de Colombia con. Decreto No 3.929 (2009). Corte Constitucional de Colombia 12 de febrero de 2009 (Control previo de constitucionalidad de decreto). Disponible en relatoría de la Corte Constitucional como sentencia C-070 de 2009, [fecha de consulta: 17 de septiembre de 2017]. [Disponible en: http://www.corteconstitucional.gov.co/relatoria/2009/C-070-09.htm].

Corte Constitucional de Colombia con. Decreto No 4.333 (2009). Corte Constitucional de Colombia 25 de febrero de 2009 (Control previo de constitucionalidad de decreto). Disponible en relatoría de la Corte Constitucional como sentencia C-135 de 2009, [fecha de consulta: 17 de septiembre de 2017]. [Disponible en: http://www.corteconstitucional.gov.co/RELATORIA/2009/C-135-09. htm]. 
Corte Constitucional de Colombia con. Decreto Legislativo No 4.490 de 2008 (2009). Corte Constitucional de Colombia 12 de marzo de 2009 (Control previo de constitucionalidad de Decreto legislativo). Disponible en relatoría de la Corte Constitucional como sentencia C-146 de 2009, [fecha de consulta: 17 de septiembre de 2017]. [Disponible en: http://www.corteconstitucional. gov.co/RELATORIA/2009/C-146-09.htm].

Guillermo Gállon Giraldo, Fátima Esparza Calderón y Astrid Orjuela Ruiz con. Ley No 1.152 de 2007 (2009). Corte Constitucional de Colombia 18 de marzo de 2009 (Acción pública de inconstitucionalidad). Disponible en relatoría de la Corte Constitucional como sentencia C-175 de 2009, [fecha de consulta: 17 de septiembre de 2017]. [Disponible en: http://www.corteconstitucional. gov.co/relatoria/2009/C-175-09.htm].

Andrea Carolina Guevara Rojas con. Ley No 300 de 1996 (2009). Corte Constitucional de Colombia 30 de marzo de 2009 (Acción pública de inconstitucionalidad). Disponible en relatoría de la Corte Constitucional como sentencia C-228 de 2009, [fecha de consulta: 17 de septiembre de 2017]. [Disponible en: http://www.corteconstitucional.gov.co/relatoria/2009/C-228-09.htm].

Guillermo Otálora Lozano con. Ley No 418 de 1997 y Ley No 599 del 2000 (2009). Corte Constitucional de Colombia 1 de abril de 2009 (Acción pública de inconstitucionalidad). Disponible en relatoría de la Corte Constitucional como sentencia C-240 de 2009, [fecha de consulta: 17 de septiembre de 2017]. [Disponible en: http://www.corteconstitucional.gov. co/relatoria/2009/c-240-09.htm].

Corte Constitucional de Colombia con. Ley No 1.203 de 2008 (2009). Corte Constitucional de Colombia 21 de abril de 2009 (Control previo de constitucionalidad de ley aprobatoria). Disponible en relatoría de la Corte Constitucional como sentencia C-288 de 2009, [fecha de consulta: 17 de septiembre de 2017]. [Disponible en: http://www.corteconstitucional.gov. co/relatoria/2009/C-288-09.htm].

Jaime Serna Giraldo con. Ley No 812 de 2003 y Ley No 1.169 de 2007 (2009). Corte Constitucional de Colombia 29 de abril de 2009 (Acción pública de inconstitucionalidad). Disponible en relatoría de la Corte Constitucional como sentencia C-307 de 2009, [fecha de consulta: 17 de septiembre de 2017]. [Disponible en: http://www.corteconstitucional.gov.co/ relatoria/2009/c-307-09.htm]. 
Jennifer Vivian Alfonso Rubiano y otros con. Ley No 1.210 de 2008 (2009). Corte Constitucional de Colombia 20 de mayo de 2009 (Acción pública de inconstitucionalidad). Disponible en relatoría de la Corte Constitucional como sentencia C-349 de 2009, [fecha de consulta: 17 de septiembre de 2017]. [Disponible en: http://www.corteconstitucional.gov.co/relatoria/2009/C-349-09. htm].

Ricardo Perilla Uribe con. Ley No 599 del 2000 (2009). Corte Constitucional de Colombia 4 de agosto de 2009 (Acción pública de inconstitucionalidad). Disponible en relatoría de la Corte Constitucional como sentencia C-521 de 2009, [fecha de consulta: 17 de septiembre de 2017]. [Disponible en: http://www.corteconstitucional.gov.co/RELATORIA/2009/C-521-09.htm]. Miller Alfonso Ramírez Solórzano con. Ley No 1.121 de 2006 (2009). Corte Constitucional de Colombia 25 de noviembre de 2009 (Acción pública de inconstitucionalidad). Disponible en relatoría de la Corte Constitucional como sentencia C-853 de 2009, [fecha de consulta: 17 de septiembre de 2017]. [Disponible en: http://www.corteconstitucional.gov.co/ relatoria/2009/C-853-09.htm].

Juan Gabriel Rojas López con. Ley No 1.333 de 2009 (2010). Corte Constitucional de Colombia 27 de julio de 2010 (Acción pública de inconstitucionalidad). Disponible en relatoría de la Corte Constitucional como sentencia C-595 de 2010, [fecha de consulta: 17 de septiembre de 2017]. [Disponible en: http://www.corteconstitucional.gov.co/relatoria/2010/c-595-10.htm].

Luis Eduardo Montealegre Lynett con. Ley No 1.333 de 2009 (2010). Corte Constitucional de Colombia 6 de septiembre de 2010 (Acción pública de inconstitucionalidad). Disponible en relatoría de la Corte Constitucional como sentencia C-703 de 2010, [fecha de consulta: 17 de septiembre de 2017]. [Disponible en: http://www.corteconstitucional.gov.co/ relatoria/2010/C-703-10.htm].

Rafael Barrios Mendivil, Dora Lucy Arias Giraldo y Linda Maria Cabrera Cifuentes con. Ley No 1.312 de 2009 (2010). Corte Constitucional de Colombia 23 de noviembre de 2010 (Acción pública de inconstitucionalidad). Disponible en relatoría de la Corte Constitucional como sentencia C-936 de 2010, [fecha de consulta: 17 de septiembre de 2017]. [Disponible en: http://www. corteconstitucional.gov.co/relatoria/2010/C-936-10.htm].

Corte Constitucional de Colombia con. Decreto No 4.580 de 2010 (2011). Corte Constitucional de Colombia 9 de marzo de 2011(Control previo de 
constitucionalidad de decreto). Disponible en relatoría de la Corte Constitucional como sentencia C-156 de 2011, [fecha de consulta: 17 de septiembre de 2017]. [Disponible en: http://www.corteconstitucional.gov.co/ RELATORIA/2011/C-156-11.htm].

Guillermo Gállon Giraldo, Fátima Esparza Calderón, Astrid Orjuela Ruiz y Mateo Gómez Vásquez con. Ley No 1.382 de 2010 (2011). Corte Constitucional de Colombia 11 de mayo de 2011 (Acción pública de inconstitucionalidad). Disponible en relatoría de la Corte Constitucional como sentencia C-366 de 2011, [fecha de consulta: 17 de septiembre de 2017]. [Disponible en: http://www.corteconstitucional.gov.co/relatoria/2011/c-366-11.htm].

Luis Eduardo Montealegre Lynett con. Ley No 1.333 de 2009 (2011). Corte Constitucional de Colombia 24 de agosto de 2011 (Acción pública de inconstitucionalidad). Disponible en relatoría de la Corte Constitucional como sentencia C-632 de 2011, [fecha de consulta: 17 de septiembre de 2017]. [Disponible en: http://www.corteconstitucional.gov.co/RELATORIA/2011/C-632-11. htm].

Corte Constitucional de Colombia con. Proyecto de ley estatutaria número 263/11 Senado y 195/11 Cámara (2012). Corte Constitucional de Colombia 12 julio de 2012 (Control previo de constitucionalidad de ley estatutaria). Disponible en relatoría de la Corte Constitucional como sentencia C-540 de 2012, [fecha de consulta: 17 de septiembre de 2017]. [Disponible en: http://www. corteconstitucional.gov.co/relatoria/2012/C-540-12.htm].

Marco Romero Silva y otros con. Ley No 1.448 de 2011 (2013). Corte Constitucional de Colombia 10 de julio de 2013 (Acción pública de inconstitucionalidad). Disponible en relatoría de la Corte Constitucional como sentencia C-438 de 2013, [fecha de consulta: 17 de septiembre de 2017]. [Disponible en: http://www.corteconstitucional.gov.co/relatoria/2013/C-438-13.htm].

Guillermo Gállon Giraldo, Fátima Esparza Calderón, Mary de la Libertad Díaz Márquez y Juan Camilo Rivera Rugeles con. Acto Legislativo No 1 de 2012 (2013). Corte Constitucional de Colombia 28 de agosto de 2013 (Acción pública de inconstitucionalidad). Disponible en relatoría de la Corte Constitucional como sentencia C-579 de 2013, [fecha de consulta: 17 de septiembre de 2017]. [Disponible en: http://www.corteconstitucional.gov. co/relatoria/2013/C-579-13.htm].

Juan Manuel Santos Calderón, Juan Carlos Moncada Zapata, Jéssica Alejandra Mancipe González, Carlos Eduardo Borrero Gonzálezy Óscar Fernando Vanegas 
Ávila con. Ley No 37 de 1961 (2014). Corte Constitucional de Colombia 2 de mayo de 2014 (Acción pública de inconstitucionalidad). Disponible en relatoría de la Corte Constitucional como sentencia C-269 de 2014, [fecha de consulta: 17 de septiembre de 2017]. [Disponible en: http://www.corteconstitucional.gov.co/relatoria/2014/c-269-14.htm].

Alberto Castilla Salazar y otros con. Ley No 1.450 de 2011 y Ley No 1.753 de 2015 (2016). Corte Constitucional de Colombia 8 de febrero de 2016 (Acción pública de inconstitucionalidad). Disponible en relatoría de la Corte Constitucional como sentencia C-035 de 2016, [fecha de consulta: 17 de septiembre de 2017]. [Disponible en: http://www.corteconstitucional.gov. co/relatoria/2016/c-035-16.htm].

Gustavo Gallón Giraldo, Josmary Ortegón Osorio y otros (2016). Corte Constitucional de Colombia 24 de febrero de 2016 (Acción pública de inconstitucionalidad). Disponible en relatoría de la Corte Constitucional como sentencia C-084 de 2016, [fecha de consulta: 17 de septiembre de 2017]. [Disponible en: http://www.corteconstitucional.gov.co/relatoria/2016/C-084-16.htm].

Corte Constitucional de Colombia con. Ley No 1.763 de 2015 (2016). Corte Constitucional de Colombia 6 de abril de 2016 (Control previo de constitucionalidad de ley aprobatoria). Disponible en relatoría de la Corte Constitucional como sentencia C-157 de 2016, [fecha de consulta: 17 de septiembre de 2017]. [Disponible en: http://www.corteconstitucional.gov.co/relatoria/2016/C-157-16.htm].

Corte Constitucional de Colombia con. Ley No 1.747 de 2014 (2016). Corte Constitucional de Colombia 14 de abril de 2016 (Control previo de constitucionalidad de ley aprobatoria). Disponible en relatoría de la Corte Constitucional como sentencia C-184 de 2016, [fecha de consulta: 17 de septiembre de 2017]. [Disponible en: http://www.corteconstitucional.gov. co/relatoria/2016/C-184-16.htm].

\section{SENTENCIAS DE UNIFICACIÓN}

Elizabeth Vargas Bermúdez, Andrés Hiber Arévalo Pacheco, Jaime Horta Díaz, Gerardo Ermilson Amortegui Calderón, Piedad Rocio Martínez Martínez, Pablo Julio Cruz Ocampo, Beatriz Vargas de Rohenes, Willy Valek Mora y Rubén Dario Acosta González con. Tribunal Administrativo del Tolima y otros, Consejo Superior de la Carrera Notarial-Superintendencia de Notariado y Registro, Gobierno Nacional-Presidente de la República, Ministerio del Interior y de Justicia, Superintendencia de Notariado y Registro y otros. (2009). Corte Constitucional 
de Colombia 11 de diciembre de 2009 (Sentencia de unificación de jurisprudencia). Disponible en relatoría de la Corte Constitucional como sentencia SU-913 de 2009, [fecha de consulta: 17 de septiembre de 2017]. [Disponible en: http://www.corteconstitucional.gov.co/relatoria/2009/SU913-09.htm]. Sandra Arabella Velásquez Salcedo contra Sala de Casación Penal de la Corte Suprema de Justicia (2012). Corte Constitucional de Colombia 12 de marzo de 2012 (Sentencia de unificación de jurisprudencia). Disponible en relatoría de la Corte Constitucional como sentencia SU-195 de 2012, [fecha de consulta: 17 de septiembre de 2017]. [Disponible en: http://www.corteconstitucional. gov.co/relatoria/2012/SU195-12.htm].

Carlos Alberto González Garizalbo y otros con Agencia Presidencial para la Acción Social y la Cooperación Internacional (2013). Corte Constitucional de Colombia 24 de abril de 2013 (Sentencia de unificación de jurisprudencia). Disponible en relatoría de la Corte Constitucional como sentencia SU-254 de 2013, [fecha de consulta: 17 de septiembre de 2017]. [Disponible en: http://www.corteconstitucional.gov.co/relatoria/2013/SU254-13.htm]. 